\title{
Performance of four HRP-2/pLDH combination rapid diagnostic tests and field microscopy as screening tests for malaria in pregnancy in Indonesia: a cross-sectional study
}

Rukhsana Ahmed ${ }^{1 *}$, Elvira I. Levy², Sylvia S. Maratina ${ }^{3}$, Judith J. de Jong ${ }^{2}$, Puji B. S. Asih ${ }^{3}$, Ismail E. Rozi ${ }^{3}$, William Hawley ${ }^{4}$, Din Syafruddin ${ }^{3}$ and Feiko ter Kuile ${ }^{1}$

\begin{abstract}
Background: Malaria in pregnancy poses a major public health problem in Indonesia with an estimated six million pregnancies at risk of Plasmodium falciparum or Plasmodium vivax malaria annually. In 2010, Indonesia introduced a screen and treat policy for the control of malaria in pregnancy at first antenatal visit using microscopy or rapid diagnostic tests (RDTs). A diagnostic study was conducted in Sumba, Indonesia to compare the performance of four different RDTs in predominately asymptomatic pregnant women under field condition.

Methods: Women were screened for malaria at antenatal visits using field microscopy and four HRP-2/pLDH combination RDTs (Carestart ${ }^{\mathrm{TM}}$, First-Response ${ }^{\circledR}$, Parascreen ${ }^{\circledR}$ and SD-Bioline ${ }^{\circledR}$ ). The test results were compared with expert microscopy and nested PCR. End user experience of the RDTs in the field was assessed by questionnaire.

Results: Overall 950 were recruited and $98.7 \%$ were asymptomatic. The prevalence of malaria was $3.0-3.4 \%$ by RDTs, and 3.6, 5.0 and $6.6 \%$ by field microscopy, expert microscopy and PCR, respectively. The geometric-mean parasite density was low (P. falciparum $=418$, P. vivax $=147$ parasites $/ \mu \mathrm{L}$ ). Compared with $P C R$, the overall sensitivity of the RDTs and field microscopy to detect any species was 24.6-31.1\%; specificities were $>98.4 \%$. Relative to PCR, FirstResponse ${ }^{\circledR}$ had the best diagnostic accuracy (any species): sensitivity $=31.1 \%$, specificity $=98.9 \%$ and diagnostic odds ratio $=39.0$ (DOR). The DOR values for Carestart ${ }^{\mathrm{TM}}$, Parascreen ${ }^{\circledR}$, SD-Bioline ${ }^{\circledR}$, and field microscopy were 23.4, 23.7, 23.5 and 29.2, respectively. The sensitivity of Pan-pLDH bands to detect PCR confirmed P. vivax mono-infection were $8.6-13.0 \%$. The sensitivity of the HRP-2 band alone to detect PCR confirmed P. falciparum was $10.3-17.9 \%$. PanpLDH detected $P$. falciparum cases undetected by the HRP-2 band resulting in a better test performance when both bands were combined. First Response ${ }^{\circledR}$ was preferred by end-users for the overall practicality.

Conclusion: The diagnostic accuracy to detect malaria among mostly asymptomatic pregnant women and perceived ease of use was slightly better with First-Response ${ }^{\circledR}$, but overall, differences between the four RDTs were small and performance comparable to field microscopy. Combination RDTs are a suitable alternative to field microscopy to screen for malaria in pregnancy in rural Indonesia. The clinical relevance of low density malaria infections detected by PCR, but undetected by RDTs or microscopy needs to be determined.
\end{abstract}

Keywords: Malaria, Pregnancy, RDT, Histidine rich protein, Screening, Field microscopy, Indonesia

\footnotetext{
*Correspondence: Rukhsana.Ahmed@|stmed.ac.uk

${ }^{1}$ Department of Clinical Sciences, Liverpool School of Tropical Medicine,

Pembroke Place, Liverpool L3 5QA, UK

Full list of author information is available at the end of the article
} 


\section{Background}

Malaria in pregnancy poses a major public health problem in Indonesia, where annually an estimated 6.3 million pregnancies are potentially at risk of Plasmodium falciparum or Plasmodium vivax malaria [1] and the corresponding risk of malaria associated maternal anaemia and low birth weight due to pre-term delivery or intra-uterine growth retardation [2-4]. Early detection and effective management of asymptomatic and symptomatic malaria is essential to reduce the burden of malaria in pregnancy.

Indonesia introduced a screen and treat policy for the control of malaria in pregnancy in 2010 [5]. It consists of screening all pregnant women for malaria at their first antenatal visit using microscopy or rapid diagnostic test (RDT), regardless of the presence or absence of symptoms. At subsequent antenatal visits, testing for malaria is done only in women with symptoms of malaria. Malaria positive women are treated with artemisininbased combination therapy (ACT, dihydroartemisininpiperaquine), except in the first trimester when quinine is used. Microscopy, remains the gold standard for malaria diagnosis in most health facilities. RDTs are used in the village based antenatal clinics.

The common immuno-chromatography based malaria RDTs detect the histidine rich protein-2 (HRP-2) antigen or parasite lactate dehydrogenase $(\mathrm{pLDH})$ enzyme. The HRP-2/pLDH combination RDTs are commonly used in Indonesia and other Asian countries where multiple Plasmodium species are endemic. The HRP-2 antigen is specific for P. falciparum and Pan-pLDH detects all human infecting species $[6,7]$.

RDTs are essential for the success of the malaria in pregnancy screening programme. Numerous studies have shown the ability of HRP-2 based RDTs to detect $P$. falciparum in symptomatic population in areas of varying transmissions [8-13]. Few studies have evaluated RDTs in pregnancy [14-16] and fewer as a screening test in pregnant women [17-20], specially to detect $P$. vivax in asymptomatic women [21-23], and under field conditions. The study aimed to assess the ability of RDTs to detect $P$. falciparum and $P$. vivax, in mostly asymptomatic pregnant women and to compare it against the performance of standard field microscopy. For this, a cross-sectional study was conducted in eastern Indonesia comparing four combination RDTs and field microscopy against expert microscopy and PCR to identify the RDT with highest diagnostic accuracy and field practicality to use as a screening test in rural antenatal clinics.

\section{Methods}

\section{Study area and facilities}

The study was conducted between March and July 2012 in south-west Sumba district in eastern Indonesia where malaria transmission is low and seasonal and varies substantially across sub-districts [24]. Prevalence of malaria in the general population (all age groups) in the rainy season (December-March) is $6.8 \%$ with a predominance of $P$. falciparum. In the dry season (April-November) both $P$. falciparum and $P$. vivax are present in equal proportions with an overall prevalence of $4.9 \%$ by PCR.

The study was conducted in 'Posyandus', which are village based community integrated activities held monthly that include provision of outreach antenatal care services provided by the primary health centres (Puskesmas). A total of 45 Posyandus were involved in the study, served by four Puskesmas in the sub-districts of Bondo-Kodi, Kori, Wallandimu and Pannengo-ede, each covering a catchment population of approximately 30,000 people and $10-11$ villages.

\section{Participant enrolment}

Pregnant women of any gravidity aged between 15 and 49 years who attended the Posyandu for routine antenatal care were enrolled. A questionnaire consisting of socio-demographic information, obstetric history, history of fever and drug use, including malaria prevention measures was completed and the axillary temperature recorded. A finger prick blood sample was taken to simultaneously test the four RDTs, malaria microscopy and dried blood spots for PCR. Women testing positive for malaria with any RDT were treated according to the national policy which was a 3 day course of ACT (dihydroartemisinin-piperaquine) in the second and third trimester and 7 days of oral quinine in the first trimester.

\section{Microscopy}

Thick and thin smears were made on the same slide and stained with $5 \%$ Giemsa. For the 'field microscopy', the smears were read by the staff microscopist at each of the four Puskesmas who were unaware of the RDT results. Thin smears were used to identify species. Expert microscopy consisted of re-examination of all the slides by the senior microscopist at the Malaria Laboratory-1, Eijkman Institute in Jakarta, who was blinded to field microscopy and RDT results. In cases of disagreement between field and expert microscopy, PCR result was taken as final. A slide was declared negative if parasites were absent after examining 200 high power fields. Parasite density was quantified against 300 leukocytes on an assumed leukocyte count of 8000 per $\mu \mathrm{L}$ of blood. Sub-microscopic infection was defined as parasites detected by PCR, but not by expert microscopy or RDT respectively.

\section{Rapid diagnostic tests}

The four RDTs included Parascreen Rapid Test Pan/ $\mathrm{Pf}^{\circledR}$ (Zephyr Biomedical System, India, Catalogue No: 
50310025), SD Bioline Malaria Ag Pf/Pan ${ }^{\circledR}$ (Standard Diagnostic Inc. Suwon City, South Korea, Catalogue No: 05FK60), the two RDTs used in the malaria control programme in Indonesia at the time of the study, and First Response Malaria pLDH/HRP-2 combo $^{\circledR}$ (Premier Medical Corporation Ltd, India, Catalogue No: 116FRC30) and CareStart Malaria pLDH/HRP2 combo ${ }^{\mathrm{TM}}$ (Access Bio Inc., NJ, USA, Catalogue No: G0131), two of the best performing RDTs indicated in the WHO/FIND round 1-3 report [25]. Trained study staff performed and interpreted the RDTs according to the manufacturer's instructions.

Accordingly, four drops of buffer were used for SD Bioline $^{\circledR}$ and read within $15 \mathrm{~min}$; for the other three RDTs two drops of buffer were used and was read within $20 \mathrm{~min}$. Malaria positivity was defined if any of the HRP-2 or pLDH bands were visible (plus the control band). If only HRP-2 band plus control band was visible it was considered as a $P$. falciparum infection and visibility of only Pan-pLDH band was considered a $P$. vivax infection. When both bands were positive simultaneously it was considered a P. falciparum infection or a mixed infection.

\section{Polymerase chain reaction}

Nested PCR was performed on all samples to detect malaria parasites and for speciation. A blood sample was spotted on Whatman grade-1 filter paper, air-dried, placed in a plastic bag and transported to Jakarta. DNA was extracted with a $20 \%$ Chelex solution and stored at $-20{ }^{\circ} \mathrm{C}$. Nested PCR based on the principle described by Snounou et al. [26] was used for genus and species specific analysis of $P$. falciparum and $P$. vivax. All ribosomal PCR positives samples were confirmed using mitochondrial DNA based PCR. Repeat mitochondrial PCR was performed for discordant $P$. vivax samples using KAPA2G $^{\text {TM }}$ Fast ReadyMix $(2 \times)$ (KAPA Bio systems) containing all components for the PCR and the primers MitoPf-F 307 and MitoPf-R 5904 and adding $2 \mu \mathrm{L}$ of DNA template. Species identification was done on PCRRestriction Fragment Length Polymorphism (Rflp) using the restriction endonuclease enzyme $A c l 1$. The amplicon was electrophoresed on $2 \%$ agarose gel and the species specific DNA bands were viewed. Staff unaware of the microscopy and the RDT results performed PCR.

\section{Quality control measures and RDT transport and storage}

Room temperature and humidity in the RDT storage rooms in the Puskesmas were monitored and recorded using Tinytag ${ }^{\mathrm{TM}}$ Data Loggers with alarms set at $40{ }^{\circ} \mathrm{C}$, the upper limit of temperature stability for SD Bioline ${ }^{\circledR}$. The recorded data was saved into the main database and verified fortnightly. The maximum humidity recorded was $82.1 \mathrm{rh} \%$ and temperature ranged between 22.8 and $28.5^{\circ} \mathrm{C}$ during the study period. To follow real-life field situations, environmental conditions in storage facilities were not controlled although excessive exposure to direct sunlight was avoided during RDT transportation. Individual kits were opened only at the time of testing and were checked for the presence of the desiccant. A single batch of each RDT with same LOT number purchased directly from the manufacturer was used.

\section{End user experience}

The ease of use and practicality of the study RDTs in the field situation was explored mid-way of the study. The Puskesmas midwives/nurses trained for the study were given a questionnaire to assess the readability and print clarity of information on the package exterior, ease of using the blood collecting devices, transferring blood to the RDT cassette and addition of buffer drops. Each parameter was scaled from easy, moderately easy and hard and the response frequency to each category calculated.

\section{Sample size}

A sample size of 940 pregnant women were estimated to be sufficient to compare RDTs with expert microscopy and PCR. Allowing for a $10 \%$ loss of samples or unsuccessful tests a target sample size of 1045 women was estimated. An anticipated malaria prevalence of $10 \%$ detectable by PCR was considered with reference to a previous study in the area [27]. This assumption would allow the detection of a sensitivity and specificity of 0.97 with a lower $95 \%$ confidence limit $>0.9$ with $95 \%$ probability.

\section{Statistical analysis}

Data were double entered and verified using XAMPP Windows 1.7.7. Frequencies and proportions were calculated using SPSS version 20.0. The results of the four RDTs and field microscopy were first compared against expert microscopy as the reference test. In subsequent analysis the RDTs, field and expert microscopy were compared against PCR (all samples) as the reference test, for any species (overall) and by specific RDT bands (HRP-2 and PLDH) against the species identified by PCR. For both sets of analyses, the sensitivity, specificity, positive and negative predictive values and likelihood ratios (LR) were calculated with corresponding $95 \%$ confidence intervals $(\mathrm{CI})$ using an online calculator which uses the efficient score method to calculate $95 \%$ CI suitable for situations where the proportion is small and prevalence is low [28]. The diagnostic odds ratio (DOR) was used as a single summary indicator of test effectiveness independent of prevalence combining sensitivity and specificity, where DOR was defined as the ratio of the odds of positivity in those with malaria (defined by PCR or expert 
microscopy) relative to the odds of positivity in those without malaria. The DOR is also the ratio of the positive and negative likelihood ratio (LR+/LR-) [29].

\section{Ethical approval}

The study was approved by the Research and Ethical Committees of the Eijkman Institute for Molecular Biology, Indonesia and the Liverpool School of Tropical Medicine, UK. Written informed consent was obtained.

\section{Results}

A total of 950 women who attended the study Posyandus for antenatal care were enrolled between March and July 2012. Most women were indigenous to southwest Sumba $(97.5 \%)$ and lived in rural areas $(100 \%)$. Their mean age (SD) was 28.8 (6.2) years and $17.8 \%$ were primigravidae. The proportion of women reporting ownership of long lasting insecticide treated nets (LLINs) was $29.9 \%$ of whom $93.3 \%$ reported to have slept under the net the previous night. A documented fever $\left(\geq 37.5{ }^{\circ} \mathrm{C}\right)$ was present in 12 of 949 women (1.3\%) and 157 (16.5\%) reported a history of fever in the previous week of whom 31 (19.7\%) reported taking anti-malarial drugs.

Malaria prevalence detected by RDTs, microscopy and PCR Overall a full set of results for the RDTs, blood smears and PCR samples were available from 934 of the 950 women. The remaining 16 women $(1.7 \%)$ were excluded from analysis because not all four RDT tests were successful or no microscopy results were available.

Malaria positivity by RDT (HRP2 or $\mathrm{pLDH}$ ) ranged from $3.0 \%$ (28 women) with Carestart ${ }^{\mathrm{TM}}$ to $3.4 \%$ (32 women) with Parascreen ${ }^{\circledR}$ (Table 1). The higher number of positives with Parascreen ${ }^{\circledR}$ relative to Carestart $^{\mathrm{TM}}$ was due to a higher number of positives by the HRP-2 band (21 versus 15). Overall, differences in results were greatest for the single Pan-pLDH band (which in the absence of a positive HRP-2 band is indicative of non-falciparum malaria infections) and positivity varied from $6.6 \%$ with SD Bioline ${ }^{\circledR}$ to $21.4 \%$ with Carestart ${ }^{\mathrm{TM}}$.

There were $34(3.6 \%)$ and $47(5.0 \%)$ malaria (any species) positives detected by field and expert microscopy respectively when both asexual and sexual stages were considered. Overall, 5 of the $34(14.7 \%)$ and 8 of the 47 $(17.0 \%)$ were positive for gametocytes by field and expert microscopy respectively. Expert microscopy detected 5 (10.6\%) mono infections with Plasmodium malariae and $5(10.6 \%)$ mixed infections with $P$. falciparum and P. vivax.

Overall infection prevalence by PCR was $6.6 \%$ (all species) and $3.9 \%$ were sub-patent infections (microscopy or RDT negative). Of the 62 positives identified by PCR, 39 (62.9\%) were with P. falciparum (32 mono-infections and seven mixed with $P$. vivax), and $23(37.0 \%)$ were $P$. vivax mono-infections. No infections with $P$. malariae were detected.

There were 31 women who had reported to have taken antimalarial drug in the previous week. Out of these, one women had all four RDTs positives, two women had a positive microscopy (6.4\%) and three women had a positive PCR (9.6\%) for any malaria.

\section{Discriminating ability of the RDTs and field microscopy PCR as reference test}

Malaria overall (any species) (Table 2): The sensitivity and specificity of the RDTs to detect malaria (any species) (positive HRP-2 or Pan-pLDH band) against PCR was relatively similar for all four RDTs. The sensitivity ranged between 25.8 and $32.3 \%$. The specificity was $>98.3 \%$ for all RDTs. First Response ${ }^{\circledR}$ had the highest combination of sensitivity and specificity, reflected in the highest LRpositive, lowest LR-negative scores and the highest DOR value (41.0, 95 \% CI 16.9-101.2). The DOR of Carestart ${ }^{\mathrm{TM}}$ (24.9), Parascreen ${ }^{\circledR}(-25.0)$ and SD Bioline ${ }^{\circledR}$ (24.9) were similar. The sensitivity of field microscopy was comparable to First Response ${ }^{\circledR}$, but the specificity and the DOR (29.1) was lower.

Plasmodium falciparum and single HRP-2 band (Table 3): The performance of the HRP-2-bands alone (i.e. ignoring the results of the Pan-pLDH band) to detect P. falciparum infections assessed by PCR, showed that the overall sensitivity ranged from $10.3 \%$ with Carestart $^{\mathrm{TM}}$ to $17.9 \%$ with Parascreen ${ }^{\circledR}$ and First Response ${ }^{\circledR}$. The PPV and DOR indices were highest for First Response ${ }^{\circledR}$ reflected by less false positives compared to other RDTS.

Plasmodium falciparum and single Pan-pLDH band (Table 4): The accuracy of pLDH band alone to detect $P$. falciparum was assessed against PCR detected mono- $P$. falciparum (after exclusion of $P$. vivax mono or mixed infection from the analysis). The sensitivity ranged from $18.8 \%$ with Parascreen ${ }^{\circledR}$ to $25.0 \%$ with First Response ${ }^{\circledR}$. The DOR was highest for SD Bioline ${ }^{\circledR}$ followed by First Response ${ }^{\circledR}$.

Plasmodium falciparum and the combined HRP-2 and Pan-pLDH bands (Table 5): The accuracy of HRP-2 and pLDH positive bands to detect $P$. falciparum was evaluated with PCR confirmed P. falciparum (any). The sensitivities ranged between 30.7 and $41.0 \%$. The LR positive and DOR values ranged between 17.2 and $24.5 \%$ for Carestart $^{\mathrm{TM}}$ and 26.2 and $44.4 \%$ for First Response ${ }^{\circledR}$, respectively.

Plasmodium vivax and Pan-pLDH band (Table 6): The performance of RDT to detect $P$. vivax was evaluated with PCR detected $P$. vivax mono-infections (after exclusion of $P$. falciparum mono or mixed infection from the analysis). The sensitivity to detect $P$. vivax was lower 
Table 1 Malaria detected by the four RDTs (HRP-2 and pLDH bands), microscopy and PCR

\begin{tabular}{|c|c|c|c|c|}
\hline & $\begin{array}{l}\text { Carestart }^{\mathrm{TM}} \\
\mathbf{n}=934\end{array}$ & $\begin{array}{l}\text { First Response }^{\circledR} \\
n=934\end{array}$ & $\begin{array}{l}\text { Parascreen }^{\circledR} \\
\mathrm{n}=934\end{array}$ & $\begin{array}{l}\text { SD Bioline }{ }^{\circledR} \\
n=934\end{array}$ \\
\hline RDT positive (any band) n (\%) & $28(3.0)$ & $30(3.2)$ & $32(3.4)$ & $30(3.2)$ \\
\hline HRP-2 band only, n (\%) & $15(53.6)$ & $17(56.6)$ & $21(65.6)$ & $20(66.6)$ \\
\hline \multicolumn{5}{|l|}{ P. falciparum confirmed by $P C R$} \\
\hline HRP-2 band, n (\%) & $4(26.7)$ & $7(41.2)$ & $7(33.3)$ & $6(30.0)$ \\
\hline Pan-pLDH band only, n (\%) & $6(21.4)$ & $6(19.4)$ & $4(12.5)$ & $2(6.6)$ \\
\hline \multicolumn{5}{|l|}{ Species confirmed by $P C R$} \\
\hline P. falciparum, n (\%) & $2(33.0)$ & $3(50.0)$ & $1(25.0)$ & $1(50.0)$ \\
\hline P. vivax, $\mathrm{n}(\%)$ & $2(33.0)$ & $2(33.0)$ & $2(50.0)$ & $1(50.0)$ \\
\hline Negative & $2(33.0)$ & $1(16.9)$ & $1(25.0)$ & 0 \\
\hline HRP2 + pLDH bands, n (\%) & $7(25.0)$ & $7(23.0)$ & $7(21.8)$ & 8 (26.6) \\
\hline \multicolumn{5}{|l|}{ Species confirmed by $P C R$} \\
\hline P. falciparum, n (\%) & $5(71.4)$ & $5(71.4)$ & $5(71.4)$ & $6(75.0)$ \\
\hline P. vivax, $\mathrm{n}(\%)$ & $1(14.3)$ & $1(14.3)$ & $1(14.3)$ & $1(12.5)$ \\
\hline \multirow[t]{3}{*}{ Mixed $(P f+P v), \mathrm{n}(\%)$} & $1(14.3)$ & $1(14.3)$ & $1(14.3)$ & $1(12.5)$ \\
\hline & Field microscopy & Expert microscopy & \multicolumn{2}{|l|}{ PCR $n=934$} \\
\hline & $n=934$ & $\mathrm{n}=934$ & Overall & Sub-microscopic ${ }^{a}$ \\
\hline Parasitaemia any, n (\%) & $34(3.6)$ & $47(5.0)$ & $62(6.6)$ & $32(3.4)$ \\
\hline P. falciparum, n (\%) & $26(76.5)$ & $24(51.1)$ & $32(51.6)$ & $20(62.5)$ \\
\hline P. vivax, $\mathrm{n}(\%)$ & $8(23.5)$ & $13(27.7)$ & $23(37.0)$ & $12(37.5)$ \\
\hline P. malariae, n (\%) & - & $5(10.6)$ & - & - \\
\hline Mixed $(P f+P v) n(\%)$ & - & $5(10.6)$ & $7(11.3)$ & - \\
\hline
\end{tabular}

Pf, P. falciparum; PV, P. vivax

a Sub-microscopic $=$ expert microscopy negative, $\mathrm{PCR}$ positive

than for P. falciparum ranging from $8.7 \%$ with SD Bioline ${ }^{\circledR}$ to $13.0 \%$ with the other three RDTs. The DOR values ranged from $10.8 \%$ with SD Bioline ${ }^{\circledR}$ to $16.9 \%$ with Parascreen ${ }^{\circledR}$. The field microscopy indices were relatively better for $P$. vivax detection with higher DOR values.

\section{Expert microscopy as reference test}

Similar results were found when RDTs and field microscopy were compared against expert microscopy to detect any malaria (Table 2). Overall, the sensitivity remained modest for all four RDTs and for field microscopy with SD Bioline ${ }^{\circledR}$ scoring better LR-positive and DOR values. When the ability to detect $P$. falciparum by HRP-2 band was assessed, First Response ${ }^{\circledR}$ had a lower false positive score reflected by higher PPV and LR-positive relative to the other RDTs (Table 3). SD Bioline ${ }^{\circledR}$ indices to detect $P$. vivax by pLDH band were relatively better than the other RDTs.

\section{RDT detection of malaria at different parasite densities}

The geometric mean parasite density of $P$. falciparum assessed by expert microscopy was 418 parasites/ $\mu \mathrm{L}$ (range 27-13,387 parasites/uL) and of $P$. vivax was 147 parasites $/ \mu \mathrm{L}$ (range $27-5733$ parasites $/ \mu \mathrm{L}$ ). Out of the 12 PCR confirmed expert microscopy positive $P$. falciparum cases, there was one case of mono-infection with $P$. falciparum at density $<100$ parasite $/ \mu \mathrm{L}$ and this was negative by all four RDTs. Similarly, there were 6 cases out of the 11 P. vivax PCR confirmed positives which has densities of $<100$ parasites/ $\mu \mathrm{L}$ detected by expert microscopy; none were detected by the RDTs (Fig. 1). The ability to detect low-density P. falciparum infections (101-499/ $\mu \mathrm{L})$ was comparable between Carestart ${ }^{\mathrm{TM}}$ (6/6) and First Response ${ }^{\circledR}(6 / 6)$ relative to Parascreen ${ }^{\circledR}$ and SD Bioline ${ }^{\circledR}$. The detection of low-density $P$. vivax infections (100$499 / \mu \mathrm{L})$ was similar in all RDTs (33.3 \%).

\section{End user experience}

The user practicality of the RDTs was evaluated among all the 50 study midwives/nurses performing RDTs in the study. Most respondents cited the pipette of SD Bioline ${ }^{\circledR}$ was the easiest to draw blood with (86.0\%) (Table 7), but to add blood into a sample well and for the overall ease of use of pipette, First Response ${ }^{\circledR}$ scored 88.0 and $96.0 \%$ respectively followed by SD Bioline ${ }^{\circledR}$. The least easy pipette to draw and dispense blood with was that 
Table 2 Accuracy indices of the RDTs and Field microscopy compared with expert microscopy and PCR to detect any malaria (HRP-2 or pLDH band; $P$. falciparum or $P$. vivax)

\begin{tabular}{|c|c|c|c|c|c|c|}
\hline & Carestart $^{\mathrm{TM}}$ & First Response $^{\circledR}$ & Parascreen $^{\circledR}$ & SD Bioline ${ }^{\circledR}$ & Field microscopy & Expert microscopy \\
\hline \multicolumn{7}{|c|}{ Expert microscopy as reference test } \\
\hline TP, FP & 20,8 & 21,9 & 21,11 & 22,8 & 21,13 & $\mathrm{~N} / \mathrm{A}$ \\
\hline $\mathrm{FN}, \mathrm{TN}$ & 27,879 & 26,878 & 26,876 & 25,879 & 26,874 & \\
\hline Sensitivity (95 \% Cl) & $42.6(31.5-50.9)$ & $44.7(33.4-53.5)$ & $44.6(30.4-59.7)$ & $46.8(35.6-55.1)$ & $44.7(32.9-54.9)$ & \\
\hline Specificity (95% Cl) & $99.1(98.5-99.5)$ & $99.0(98.4-99.5)$ & $98.7(97.7-99.3)$ & $99.1(98.5-99.5)$ & $98.5(97.9-99.1)$ & \\
\hline PPV (95 \% Cl) & $71.4(52.9-85.4)$ & $70.0(52.3-83.8)$ & $65.6(46.7-80.8)$ & $73.3(55.8-86.3)$ & $61.8(45.5-75.8)$ & \\
\hline NPV $(95 \%$ Cl) & $97.0(96.4-97.5)$ & $97.1(96.5-97.6)$ & $97.1(95.7-98.0)$ & $97.2(96.7-86.3)$ & $97.1(96.5-97.6)$ & \\
\hline LR positive (95 \% Cl) & $47.2(21.2-110.3)$ & $44.0(20.7-97.3)$ & $36.0(18.4-70.3)$ & $51.9(23.8-119.4)$ & $30.4(15.7-59.3)$ & \\
\hline LR negative (95 \% CI) & $0.58(0.49-0.69)$ & $0.56(0.47-0.67)$ & $0.56(0.43-0.72)$ & $0.54(0.45-0.65)$ & $0.56(0.46-0.68)$ & \\
\hline DOR (95 \% Cl) & $81.4(30.5-223.4)$ & 78.7 (30.6-207.9) & $64.3(26.3-168.8)$ & 96.7 (36.4-264.7) & $54.3(27.9-130.1)$ & \\
\hline \multicolumn{7}{|l|}{$P C R$ as the reference test } \\
\hline TP, FP & 16,12 & 20,10 & 18,14 & 17,13 & 20,14 & 30,17 \\
\hline $\mathrm{FN}, \mathrm{TN}$ & 46,860 & 42,862 & 44,858 & 45,859 & 42,858 & 32,855 \\
\hline Sensitivity (95 \% Cl) & $25.8(15.8-38.7)$ & $32.3(21.2-45.4)$ & $29.0(18.5-42.1)$ & $27.4(17.2-40.4)$ & $32.2(17.2-40.4)$ & $48.4(35.6-61.3)$ \\
\hline Specificity (95 \% Cl) & $98.6(97.5-99.2)$ & $98.8(97.8-99.4)$ & $98.3(97.2-99.0)$ & $98.5(97.3-99.1)$ & $98.3(97.2-99.0)$ & $98.0(96.8-98.8)$ \\
\hline PPV (95 \% Cl) & $57.1(37.4-74.9)$ & $66.6(47.1-82.0)$ & $56.2(37.8-73.1)$ & $56.6(37.6-74.0)$ & $58.8(40.8-74.8)$ & $63.8(48.4-76.9)$ \\
\hline NPV (95 \% Cl) & $94.9(93.2-96.2)$ & $95.3(93.7-96.5)$ & $95.1(93.4-96.3)$ & $95.0(93.3-96.3)$ & $95.3(93.6-96.5)$ & $96.3(94.8-97.4)$ \\
\hline LR positive (95 \% Cl) & $18.7(9.2-37.8)$ & $28.2(13.7-57.4)$ & $18.8(9.4-34.6)$ & $18.3(9.3-36.1)$ & $20.0(10.6-37.8)$ & $24.8(14.5-42.4)$ \\
\hline LR negative (95 \% Cl) & $0.75(0.65-0.87)$ & $0.68(0.57-0.81)$ & $0.72(0.61-0.84)$ & $0.73(0.63-0.85)$ & $0.68(0.57-0.81)$ & $0.52(0.41-0.69)$ \\
\hline DOR (95 \% Cl) & $24.9(10.4-60.1)$ & $41.0(16.9-101.2)$ & $25.0(11.0-57.4)$ & $24.9(10.7-58.6)$ & $29.1(12.9-66.1)$ & $47.1(22.4-100.2)$ \\
\hline
\end{tabular}

$T P$ true positive, $F P$ false positive, $F N$ false negative, $T N$ true negative, $P P V$ positive predictive value, $N P V$ negative predictive value, $L R$ likelihood ratio, $D O R$ diagnostic odds ratio

of Parascreen ${ }^{\circledR}$. All respondents found the buffer bottles comparatively easy to use and add the right amount of drops. First Response ${ }^{\circledR}$ scored highest for overall ease of use, whereas SD Bioline ${ }^{\circledR}$ scored highest for clarity and readability of printed information provided with the RDT.

\section{Discussion}

The performance of SD Bioline ${ }^{\circledR}$, Carestart $^{\mathrm{TM}}$, First Response $^{\circledR}$ and Parascreen ${ }^{\circledR}$ RDTs to screen mostly asymptomatic antenatal women for malaria were evaluated in four sub-districts of South west Sumba, Indonesia as a potential alternative to field microscopy. Overall the diagnostic accuracy, suggested that First Response ${ }^{\circledR}$ RDT had the best combined ability to detect both $P$. falciparum and $P$. vivax infections when compared against PCR. The diagnostic odds ratio (DOR) value for First Response $^{\circledR}$, as a single summary indicator of test performance, was lower than that observed for expert microscopy but higher than the 23-29 DOR values observed for the other RDTs. First Response ${ }^{\circledR}$ was also considered the easiest to use by the clinic staff. Nevertheless, the overall differences in performance of the four RDTs to detect malaria were small and importantly, comparable to field microscopy. Any of the four brands would probably be suitable as a potential alternative to field microscopy or for use in the clinics where microscopy is not available.

However, of note was the low sensitivity (26-32 \%) of all four RDTs (and field microscopy) relative to PCR, which detected 2-3 additional infections for each infection detected by RDT. These findings are consistent with the known limitations of this current generation of RDTs and highlight the challenge of applying them as a screening test in asymptomatic pregnant women who on average will have much lower parasite densities when infected than symptomatic malaria patients, the intended population for whom most RDTs are used. The geometric mean parasite densities in those with detectable parasites by expert microscopy were low for both species, especially for $P$. vivax (418 parasites/ $\mu \mathrm{L}$ for P. falciparum and 147 parasites $/ \mu \mathrm{L}$ for $P$. vivax by expert microscopy). None of the infections (any species) below 100 parasites/ $\mu \mathrm{L}$ were detected by RDTs, around the threshold level of detection for many RDTs [25].

The sensitivity was also low when compared against expert microscopy (43.0-47.0\%, any species) and lower than reported in previous studies in asymptomatic pregnant women during pregnancy and at delivery [13]. In addition to the low mean parasite densities mentioned above, other methodological differences could explain 
Table 3 Accuracy indices of the HRP-2 band and Field microscopy compared with expert microscopy and PCR to detect $P$. falciparum

\begin{tabular}{|c|c|c|c|c|c|c|}
\hline & Carestart $^{\mathrm{TM}}$ & First Response ${ }^{\circledR}$ & Parascreen ${ }^{\circledR}$ & SD Bioline ${ }^{\circledR}$ & Field microscopy & Expert microscopy \\
\hline \multicolumn{7}{|c|}{ Expert microscopy as reference test } \\
\hline TP, FP & 7,8 & 9,8 & 8,13 & 9,11 & 13,13 & N/A \\
\hline FN, TN & 17,902 & 15,902 & 16,897 & 15,899 & 11,897 & \\
\hline Sensitivity $(95 \% \mathrm{Cl})$ & $29.2(13.4-51.2)$ & $37.5(19.6-59.2)$ & $33.3(16.4-55.3)$ & $37.5(19.6-59.2)$ & $54.2(33.2-73.8)$ & \\
\hline Specificity (95 \% Cl) & $99.1(98.2-99.6)$ & 99.1 (98.2-99.6) & $98.6(97.5-99.2)$ & $98.8(97.8-99.4)$ & $98.6(97.5-99.2)$ & \\
\hline PPV $(95 \%$ CI) & $46.7(22.3-72.6)$ & $52.9(28.5-76.1)$ & $38.1(19.0-61.3)$ & $45.0(23.8-67.7)$ & $50.0(30.4-69.6)$ & \\
\hline NPV (95 \% Cl) & $98.2(97.0-98.9)$ & $98.4(97.3-99.0)$ & $98.2(97.1-99.0)$ & $98.4(97.2-99.0)$ & $98.8(97.8-99.4)$ & \\
\hline LR positive (95 \% Cl) & $33.2(13.1-84.1)$ & $42.7(18.0-101.0)$ & $23.3(10.7-51.0)$ & $31.0(14.2-67.8)$ & $37.9(19.7-72.9)$ & \\
\hline LR negative (95 \% Cl) & $0.71(0.55-0.92)$ & $0.63(0.46-0.86)$ & $0.68(0.51-0.90)$ & $0.63(0.46-0.86)$ & $0.46(0.30-0.72)$ & \\
\hline DOR $(95 \% \mathrm{Cl})$ & $46.4(13.3-163.3)$ & $67.7(20.4-228.7)$ & $34.5(11.2-105.7)$ & $49.0(15.9-152.9)$ & $81.5(30.0-243.0)$ & \\
\hline \multicolumn{7}{|l|}{$P C R$ as the reference test } \\
\hline TP, FP & 4,11 & 7,10 & 7,14 & 6,14 & 12,14 & 12,12 \\
\hline $\mathrm{FN}, \mathrm{TN}$ & 35,884 & 32,885 & 32,881 & 33,881 & 27,881 & 27,883 \\
\hline Sensitivity (95 \% Cl) & $10.3(3.3-25.2)$ & $17.9(8.1-34.1)$ & $17.9(8.1-34.1)$ & $15.4(6.4-31.2)$ & $30.8(17.5-47.7)$ & $30.8(17.5-47.7)$ \\
\hline Specificity (95 \% CI) & $98.8(97.7-99.4)$ & 98.9 (97.9-99.4) & $98.4(97.3-99.1)$ & $98.4(97.3-99.1)$ & $98.4(97.3-99.1)$ & $98.7(97.6-99.2)$ \\
\hline PPV (95 \% Cl) & 26.7 (8.9-55.2) & $41.2(19.4-66.5)$ & $33.3(15.5-56.9)$ & $30.0(12.8-54.3)$ & $46.2(27.1-66.3)$ & $50.0(29.6-70.4)$ \\
\hline NPV (95 \% Cl) & $96.2(94.7-97.3)$ & $96.5(95.1-97.6)$ & 96.5 (95.0-97.6) & 96.4 (94.9-97.5) & $97.0(95.6-98.0)$ & $97.0(95.7-98.0)$ \\
\hline LR positive (95 \% Cl) & $8.3(2.8-25.0)$ & $16.1(6.5-40.0)$ & $11.5(4.9-26.8)$ & $9.8(4.0-24.2)$ & $19.7(9.8-39.7)$ & $22.9(11.0-47.8)$ \\
\hline LR negative (95\% Cl) & $0.9(0.82-1.01)$ & $0.83(0.72-0.96)$ & $0.83(0.72-96.5)$ & $0.86(0.75-0.98)$ & $0.70(0.57-0.87)$ & $0.70(0.57-0.87)$ \\
\hline DOR (95 \% CI) & $9.2(2.3-33.4)$ & $19.4(6.2-59.9)$ & $13.8(4.7-39.8)$ & $11.4(3.7-34.6)$ & $30.0(10.9-71.9)$ & $32.7(12.4-86.9)$ \\
\hline
\end{tabular}

$T P$ true positive, $F P$ false positive, $F N$ false negative, $T N$ true negative, $C l$ confidence interval, $P P V$ positive predictive value, $N P V$ negative predictive value, $L R$ Likelihood ratio, DOR diagnostic odds ratio

Table 4 Accuracy indices of the pLDH band compared with expert microscopy and PCR to detect $P$. falciparum

\begin{tabular}{|c|c|c|c|c|}
\hline & Carestart $^{\mathrm{TM}}$ & First Response $^{\circledR}$ & Parascreen $^{\circledR}$ & SD Bioline ${ }^{\circledR}$ \\
\hline \multicolumn{5}{|c|}{ Expert microscopy as the reference } \\
\hline TP, FP & 7,6 & 6,7 & 6,5 & 6,4 \\
\hline $\mathrm{FN}, \mathrm{TN}$ & 17,904 & 18,903 & 18,905 & 18,906 \\
\hline Sensitivity (95 \% Cl) & $29.2(13.4-51.2)$ & $25(10.6-47.1)$ & $25(10.6-47.1)$ & $25(10.6-47.1)$ \\
\hline Specificity (95 \% Cl) & $99.3(98.5-99.7)$ & $99.2(98.3-99.7)$ & $99.5(98.6-99.8)$ & $99.6(98.8-99.9)$ \\
\hline PPV (95 \% Cl) & $53.8(26.1-79.6)$ & $46.1(20.4-73.9)$ & $54.5(24.6-81.9)$ & $60(27.4-86.3)$ \\
\hline NPV $(95 \% \mathrm{Cl})$ & $98.2(96.9-98.8)$ & $98.0(96.7-98.8)$ & $98(96.9-98.8)$ & $98.1(96.9-98.8)$ \\
\hline LR positive (95\% Cl) & $44.2(16.1-121.7)$ & $32.5(11.8-89.4)$ & $45.5(14.9-138.8)$ & $56.9(17.2-188.5)$ \\
\hline LR negative (95 \% Cl) & $0.71(0.55-0.92)$ & $0.76(0.60-0.95)$ & $0.75(0.60-0.95)$ & $0.75(0.60-0.95)$ \\
\hline DOR (95\% Cl) & $62(16.5-239.0)$ & $43(11.4-162.7)$ & $60.3(14.5-257.2)$ & $75.5(16.9-356.3)$ \\
\hline \multicolumn{5}{|l|}{$P C R$ as the reference } \\
\hline TP, FP & 7,6 & 8,5 & 6,5 & 7,3 \\
\hline $\mathrm{FN}, \mathrm{TN}$ & 25,896 & 24,897 & 26,897 & 25,899 \\
\hline Sensitivity (95 \% Cl) & $21.9(9.9-40.4)$ & $25(12.1-43.8)$ & $18.8(7.9-37.0)$ & $21.9(9.9-40.4)$ \\
\hline Specificity (95 \% Cl) & $99.3(98.4-99.7)$ & $99.4(98.6-99.8)$ & $99.4(98.6-99.8)$ & $99.7(98.9-99.9)$ \\
\hline PPV (95 \% Cl) & $53.8(26.1-79.6)$ & $61.5(32.2-84.9)$ & $54.5(24.6-81.9)$ & $70(35.4-91.9)$ \\
\hline NPV (95 \% Cl) & $97.3(96.0-98.2)$ & $97.4(96.1-98.3)$ & $97.2(95.8-98.1)$ & $97.3(96.0-98.2)$ \\
\hline LR positive (95 \% Cl) & $32.9(11.7-92.3)$ & $45.1(15.6-130.2)$ & $33.8(10.9-105.1)$ & $65.8(17.8-242.7)$ \\
\hline LR negative (95\% Cl) & $0.79(0.65-0.94)$ & $0.75(0.62-0.92)$ & $0.82(0.69-0.97)$ & $0.78(0.65-0.94)$ \\
\hline DOR (95 \% Cl) & $41.8(11.5-154.1)$ & $59.8(16.2-230.7)$ & $41.4(10.3-169.9)$ & $83.9(18.0-439.7)$ \\
\hline
\end{tabular}

$T P$ true positive, $F P$ false positive, $F N$ false negative, $T N$ true negative, $C l$ confidence interval, $P P V$ positive predictive value, $N P V$ negative predictive value, $L R$ likelihood ratio, DOR diagnostic odds ratio 
Table 5 Accuracy indices of the RDTs (HRP-2 and pLDH) bands compared with PCR to detect P. falciparum

\begin{tabular}{|c|c|c|c|c|}
\hline & Carestart & First Response & Parascreen & SD Bioline \\
\hline \multicolumn{5}{|l|}{ PCR as reference test } \\
\hline TP, FP & 12,16 & 16,14 & 14,18 & 14,16 \\
\hline $\mathrm{FN}, \mathrm{TN}$ & 27,879 & 23,881 & 25,887 & 25,879 \\
\hline Sensitivity $(95 \% \mathrm{Cl})$ & $30.7(17.5-47.7)$ & $41.0(25.9-57.8)$ & $35.8(21.6-52.8)$ & $35.8(21.6-52.8)$ \\
\hline Specificity $(95 \%$ Cl) & $98.2(97.0-98.9)$ & $98.4(97.3-99.1)$ & $97.9(96.7-98.7)$ & $98.2(97.0-98.9)$ \\
\hline PPV (95 \% Cl) & $42.8(25.0-62.5)$ & $53.3(34.6-71.2)$ & $43.7(26.8-62.1)$ & $46.6(28.7-65.3)$ \\
\hline NPV (95\% Cl) & $97.0(95.6-97.9)$ & $97.4(96.1-98.3)$ & $97.2(95.8-98.1)$ & $97.2(95.8-98.1)$ \\
\hline LR positive (95 \% Cl) & $17.2(8.7-33.8)$ & $26.2(13.8-49.8)$ & $17.8(9.6-33.1)$ & $20.1(10.6-38.1)$ \\
\hline LR negative (95\% Cl) & $0.7(0.44-1.28)$ & $0.59(0.46-0.78)$ & $0.65(0.52-0.83)$ & $0.65(0.52-0.82)$ \\
\hline DOR (95 \% Cl) & $24.5(9.7-61.2)$ & $44.4(17.8-108.9)$ & $27.3(11.3-65.6)$ & $30.9(12.5-75.5)$ \\
\hline
\end{tabular}

$T P$ true positive, $F P$ false positive, $F N$ false negative, $T N$ true negative, $C l$ confidence interval, $P P V$ positive predictive value, $N P V$ negative predictive value, $L R$ likelihood ratio, DOR diagnostic odds ratio; include positives for mixed species

Table 6 Accuracy indices of the pLDH bands and Field microscopy compared with expert microscopy and PCR for the detection of $P$. vivax

\begin{tabular}{|c|c|c|c|c|c|c|}
\hline & Carestart $^{\mathrm{TM}}$ & First Response ${ }^{\circledR}$ & Parascreen $^{\circledR}$ & SD Bioline ${ }^{\circledR}$ & Field microscopy & Expert microscopy \\
\hline \multicolumn{7}{|c|}{ Expert microscopy as reference test } \\
\hline TP, FP & 3,10 & 2,11 & 2,9 & 2,8 & 0,8 & N/A \\
\hline $\mathrm{FN}, \mathrm{TN}$ & 19,911 & 11,910 & 11,912 & 11,913 & 13,913 & \\
\hline Sensitivity (95 \% CI) & $13.6(3.6-36.0)$ & $15.4(2.7-46.3)$ & $15.4(2.7-46.3)$ & $15.4(2.7-46.3)$ & 0 & \\
\hline Specificity $(95 \%$ Cl) & $98.9(97.9-99.4)$ & $98.8(97.8-99.4)$ & $99.0(98.1-99.5)$ & $99.1(98.2-99.6)$ & $99.1(98.2-99.6)$ & \\
\hline PPV (95 \% Cl) & $23.1(6.2-54.0)$ & $15.4(2.7-46.3)$ & $18.2(3.2-52.2)$ & $20.0(3.5-55.8)$ & 0 & \\
\hline NPV (95 \% Cl) & $98.0(96.8-98.7)$ & $98.8(97.8-99.4)$ & $98.8(97.8-99.4)$ & $98.8(97.8-99.4)$ & $98.6(97.5-99.2)$ & \\
\hline LR positive (95 \% Cl) & $12.6(6.6-68.3)$ & $12.9(3.2-52.4)$ & $15.7(3.8-65.9)$ & $17.7(4.2-75.5)$ & 0 & \\
\hline LR negative (95 \% Cl) & $0.87(0.74-1.03)$ & $0.86(0.68-1.08)$ & $0.85(0.68-1.08)$ & $0.85(0.67-1.07)$ & $1(1.0-1.0)$ & \\
\hline DOR (95 \% Cl) & $14.4(2.9-63.7)$ & $15.0(2.0-86.3)$ & $18.4(2.4-109.8)$ & $20.8(2.7-126.8)$ & 0 & \\
\hline \multicolumn{7}{|l|}{$P C R$ as the reference test } \\
\hline TP, FP & 3,10 & 3,10 & 3,8 & 2,8 & 4,4 & 11,2 \\
\hline $\mathrm{FN}, \mathrm{TN}$ & 20,901 & 20,901 & 20,903 & 21,903 & 19,907 & 12,909 \\
\hline Sensitivity (95 \% Cl) & $13.0(3.4-34.7)$ & $13.0(3.4-34.7)$ & $13.0(3.4-34.7)$ & $8.7(1.5-29.5)$ & $17.4(5.7-39.5)$ & $47.8(27.4-68.9)$ \\
\hline Specificity $(95 \%$ Cl) & 98.9 (97.9-99.4) & $98.9(97.9-99.4)$ & 99.1 (98.2-99.6) & 99.1 (98.2-99.6) & $99.6(98.8-99.9)$ & $99.8(99.1-100.0)$ \\
\hline PPV (95 \% Cl) & $23.1(6.2-54.0)$ & $23.1(6.2-54.0)$ & $27.3(7.3-60.7)$ & $20.0(3.5-55.8)$ & $50.0(1.7-82.6)$ & $84.6(53.7-97.3)$ \\
\hline NPV (95 \% Cl) & $97.8(96.6-98.6)$ & 97.8 (96.6-98.6) & $97.8(96.6-98.6)$ & $97.7(96.5-98.6)$ & $97.9(96.8-98.7)$ & $98.7(97.7-99.3)$ \\
\hline LR positive (95 \% Cl) & $11.9(3.5-40.3)$ & $11.9(3.5-40.3)$ & $14.9(4.2-52.4)$ & $9.9(2.2-44.1)$ & $39.6(10.6-148.7)$ & $217.8(51.2-927.5)$ \\
\hline LR negative (95 \% Cl) & $0.88(0.75-1.03)$ & $0.88(0.75-0.84)$ & $0.88(0.75-1.03)$ & $0.92(0.81-1.04)$ & $0.83(0.69-1.00)$ & $0.52(0.35-0.77)$ \\
\hline DOR (95 \% Cl) & $13.5(2.7-59.5)$ & $13.5(2.7-59.5)$ & $16.9(3.2-78.2)$ & $10.8(1.5-60.1)$ & $47.7(9.1-251.4)$ & $416.6(74.1-3087.2)$ \\
\hline
\end{tabular}

$T P$ true positive, $F P$ false positive, $F N$ false negative, $T N$ true negative, $C l$ confidence interval, $P P V$ positive predictive value, $N P V$ negative predictive value, $L R$ likelihood ratio, $D O R$ diagnostic odds ratio

the lower sensitivity. First, the expert microscopist declared a slide negative after examining 200 instead of the commonly used 100 high power fields, thus doubling the volume of blood that was examined to enhance the sensitivity of microscopy. Second, several previous studies showed that diagnostic studies with imperfect gold standard such as microscopy can lead to bias, the direction of which depends on the correlation between the index and reference test [30]. To overcome this, some studies comparing RDT against microscopy use PCR as the resolver test. However, when PCR is conducted on discrepant samples only, it has potential for upward bias overestimating sensitivity and specificity [31-33] compared to studies that also test a random sample of concordant negative samples as recommended by WHO [34], or conduct PCR on all samples regardless of the 


\section{a Carestart First Resposne $\square$ Parascreen $\square$ SD Bioline}
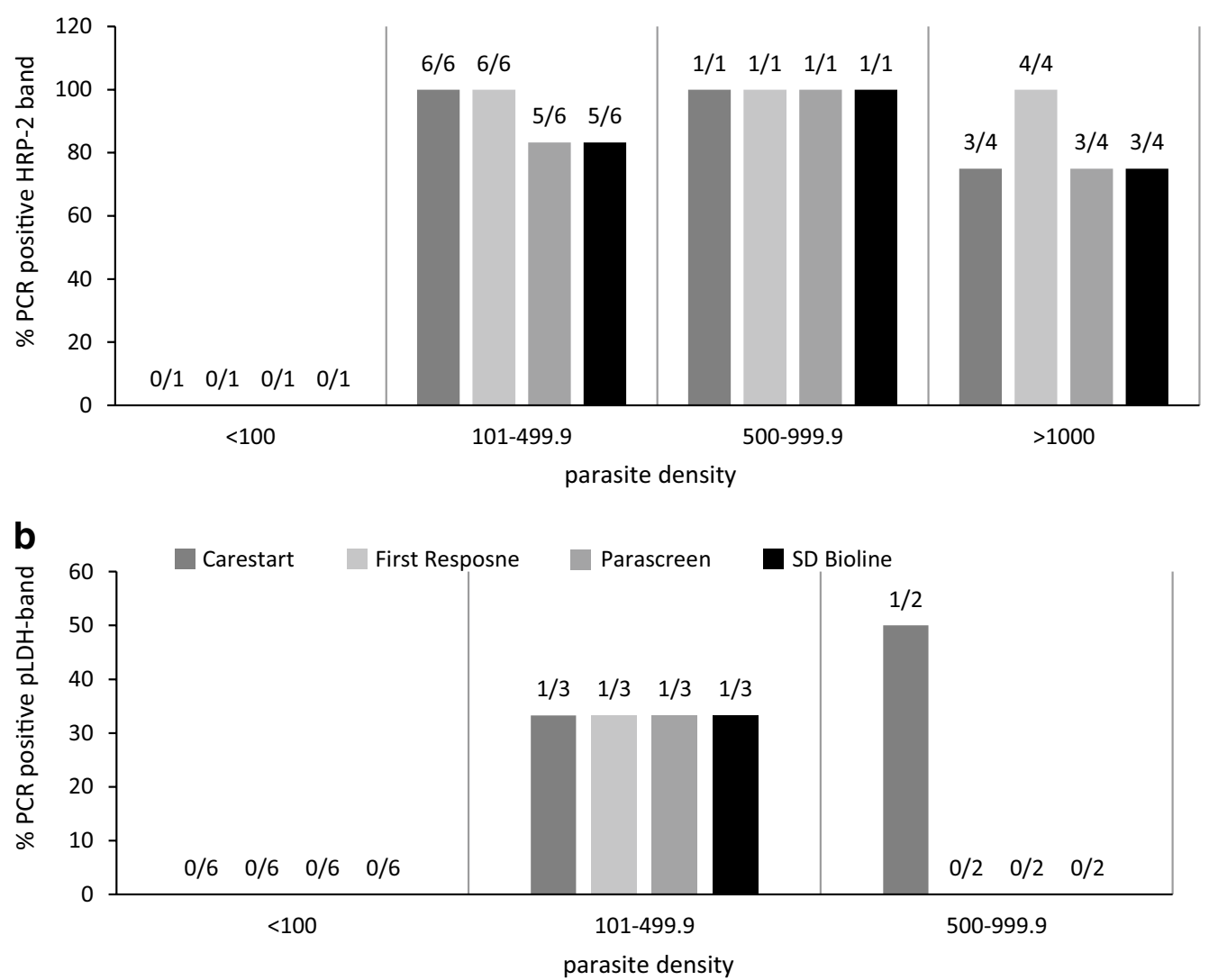

Fig. 1 Detection of Plasmodium falciparum and Plasmodium vivax by the HRP-2 and pLDH bands at different parasite densities. a P. falciparum detection by HRP-2bands in PCR positive cases stratified by microscopy density. Figures above the bars are HRP-2 positive bandscorresponding to each parasite threshold out of the total 12 PCR versus expert microscopy confirmed $P$. falciparum results; excludes mixed RDT infection. b. P. vivax detection by pLDH band in PCR positive cases stratified by microscopy density. Figures above the bars are the pLDH bands corresponding to each parasite threshold out of the total 11 PCR versus expert microscopy confirmed $P$. vivax results; none of the PCR confirmed vivax positives had parasite density > 1000/ $\mu \mathrm{L}$; excludes mixed RDT infection

Table 7 Response frequencies of the parameters assessed for end user practicality of the four RDTs

\begin{tabular}{|c|c|c|c|c|}
\hline Parameter & $\begin{array}{l}\text { Carestart }^{\mathrm{TM}} \\
\mathrm{n}=50\end{array}$ & $\begin{array}{l}\text { First Response }{ }^{\circledR} \\
\mathbf{n}=50\end{array}$ & $\begin{array}{l}\text { Parascreen }^{\circledR} \\
\mathrm{n}=50\end{array}$ & $\begin{array}{l}\text { SD Bioline }^{\circledR} \\
n=50\end{array}$ \\
\hline \multicolumn{5}{|l|}{ Pipette use } \\
\hline Easy to draw right amount of blood, n (\%) & $39(78.0)$ & $40(80.0)$ & $30(60.0)$ & $43(86.0)$ \\
\hline Easy to dispense blood into well, n (\%) & $44(88.0)$ & $44(88.0)$ & $22(44.0)$ & $43(86.0)$ \\
\hline Overall ease of use, n (\%) & $45(90.0)$ & $48(96.0)$ & $27(54.0)$ & $46(92.0)$ \\
\hline \multicolumn{5}{|l|}{ Buffer bottle } \\
\hline Easy to dispense drops into well, n (\%) & $36(72.0)$ & $37(74.0)$ & $38(76.0)$ & $36(72.0)$ \\
\hline \multicolumn{5}{|l|}{ Package exterior information } \\
\hline Easy to read and print clarity, n (\%) & $44(88.0)$ & $38(76.0)$ & $46(92.0)$ & $45(90.0)$ \\
\hline \multicolumn{5}{|l|}{ Overall ease of use ${ }^{a}$} \\
\hline Easy, n (\%) & $36(72.0)$ & $40(80.0)$ & $37(74.0)$ & $41(82.0)$ \\
\hline Moderately easy, n (\%) & $7(14.0)$ & $3(6.0)$ & $6(12.0)$ & $6(12.0)$ \\
\hline Hard to use, n (\%) & $6(12.0)$ & $6(12.0)$ & $6(12.0)$ & $2(4.0)$ \\
\hline
\end{tabular}

a One response is missing for this parameter 
RDT and microscopy results, as done in this study. E.g. if only PCR was used for the discordant RDT-microscopy samples in our study, the sensitivity of the RDTs against expert microscopy would increase from 40-50 \% to 75.0$87.0 \%$, comparable to findings in other low transmission areas such as in India where $P$. falciparum and $P$. vivax co-exist [10].

The sensitivity of the Pan-pLDH band to detect (PCR confirmed) P. vivax mono-infections (Table 6) was particularly low relative to PCR whereas field microscopy performed slightly better as indicated by higher DOR value (40 for field microscopy versus 10-12 for the PanpLDH RDTs bands). Six out of 11 infections detected by expert microscopy had densities below 100 parasites per/ $\mu \mathrm{L}$ and none of them were detected by RDTs. The low parasite densities of $P$. vivax might explain the low sensitivity of the pLDH bands to detect $P$. vivax. Studies in Myanmar and Madagascar with comparable transmission level to Indonesia also found decreased accuracy of Pan-pLDH to $P$. vivax with decreasing parasite density [21, 35].

Interestingly, Pan-pLDH detected $P$. falciparum cases that were negative by the HRP-2 band resulting in a better test performance when results of both bands were combined (Table 5). It is not known whether genetic variation in P. falciparum histidine rich protein, such as described in parasites from the Peruvian Amazon [36], some of which lack PfHRP2 or PfHRP3, and the extensive variation observed recently as a possible cause of variable sensitivity of the HRP2 band among Indian P. falciparum parasite populations [37] exist in Indonesia and if they affect PfHRP concentrations.

The low parasite densities for $P$. vivax may also explain the lack of agreement between expert and field microscopy as none of the 8 smears classified as $P$. vivax by field microscopy (4 of which were PCR confirmed) were confirmed by expert microscopy, and none of the $13 P$. vivax infections detected by expert microscopy (11 of which were PCR confirmed) were detected by field microscopy.

Comparison between other RDT studies in pregnancy and this study was problematic because of the differences in transmission level, endemic species, RDT brands and analysis method used. Earlier studies have used RDTs to diagnose placental malaria at delivery [15, 16, 38]. Most African studies have used HRP-2 based RDTs to diagnose malaria in pregnancy and assessed for P. falciparum detection [39-41]. Other studies that used RDTs to screen pregnant women have used different brands at different transmission settings $[18,20]$.

To qualify for an effective screening test used in low malaria prevalent population, the RDTs should have an acceptable balance to "rule-out" and "rule-in" infections in asymptomatic women. The RDTs demonstrated these qualities for any malaria detection and their performance overall (any species) was similar to field microscopy. The high specificity and NPV indicated that the RDTs correctly identified non-infected women, which would avoid treating women without malaria.

The perceived ease of use by the field staff for the four RDTs were comparable. When the package readability was accounted for, SD Bioline ${ }^{\circledR}$ was favoured whereas First Response ${ }^{\circledR}$ was preferred for overall practicality including ease of blood transfer pipette and buffer usage. The loop pipette for blood transferring found in Parascreen ${ }^{\circledR}$ kit was preferred least, similar to studies elsewhere [42]. A very useful advantage of the RDTs over microscopy was that women could be shown the RDT results, which made the RDTs more acceptable to asymptomatic women and which is likely to enhance compliance with any 3-day $\mathrm{ACT}$ regimen required to treat the malaria infection.

Limitations of our study included the cross sectional study design, which limited determining when submicroscopic infections may become patent and we were unable to follow women until delivery to correlate antenatal RDT findings with placental malaria. Batch quality Lot testing prior to using the RDTs was not performed. The study environment with dedicated research staff who were trained for the study and attention given to operational conditions, might not reflect the routine field situations.

\section{Conclusions}

The diagnostic accuracy to detect malaria among mostly asymptomatic pregnant women and perceived ease of use by field staff was slightly better with First Response ${ }^{\circledR}$, but overall differences between the four RDTs were small and performance was comparable to field microscopy. Best test performance to detect $P$. falciparum was achieved by combining the results of both $\mathrm{pLDH}$ and the HRP-2 bands. Combination RDTs are a suitable alternative to field microscopy to screen for malaria in pregnancy in rural Indonesia. However both RDTs and field microscopy missed many infections detected by PCR, especially $P$. vivax infections. The clinical relevance of these low density infection needs to be determined further, as it may help determine whether preventive strategies such as intermittent preventive therapy in pregnancy (IPTp) may be more effective than single or repeated screening with RDTs during pregnancy.

\section{Authors' contributions}

RA, FtK, WH, DS conceived the study and RA, FtK designed it. RA led the field work, data analysis, interpretation and drafted the first manuscript. EIL was engaged in data collection, cleaning, analysis and contributed to data interpretation. JDJ contributed to data collection, data entry and cleaning. SSM assisted in field work and performed the PCR with input from PBSA. IER set up and managed the data entry screen. DS supervised the laboratory procedures 
and PCR quality control. FtK oversaw the study design and provided input to data analysis, interpretation and the drafting of first manuscript. All authors contributed to the final submitted version of the manuscript. All authors read and approved the final manuscript.

\section{Author details}

${ }^{1}$ Department of Clinical Sciences, Liverpool School of Tropical Medicine, Pembroke Place, Liverpool L3 5QA, UK. ${ }^{2}$ Academic Medical Centre, University of Amsterdam, Amsterdam, The Netherlands. ${ }^{3}$ Malaria Laboratory, Eijkman Institute for Molecular Biology, Jakarta, Indonesia. ${ }^{4}$ UNICEF, Jakarta, Indonesia.

\section{Acknowledgements}

We thank the pregnant women who participated in the study, the study staff for data collection, the field and expert microscopist for examining the slides and Dr Fatmawaty Ahmad for her role in the field work. We appreciate the cooperation of the Heads of the Community Health Centres (Puskesmas) and midwife coordinators of the participating Puskesmas. We acknowledge the support of the Head of District Health Office and Malaria Section of the District Health Office, SW Sumba. Funding for this work was supported by a Special Service Agreement (SSA No: SSA/IDSA/2011/00002000-1) between the Liverpool School of Tropical Medicine, UK and UNICEF, Indonesia. The findings and conclusions in this paper are those of the authors and do not necessarily represent the views of the UNICEF, Indonesia.

\section{Competing interests}

The authors declare they have no competing interests.

Received: 27 May 2015 Accepted: 11 October 2015

Published online: 29 October 2015

\section{References}

1. Dellicour S, Tatem AJ, Guerra CA, Snow RW, ter Kuile FO. Quantifying the number of pregnancies at risk of malaria in 2007: a demographic study. PLoS Med. 2010;7:e1000221.

2. Desai M, ter Kuile FO, Nosten F, McGready R, Asamoa K, Brabin B, Newman $\mathrm{RD}$. Epidemiology and burden of malaria in pregnancy. Lancet Infect Dis. 2007;7:93-104.

3. Poespoprodjo JR, Fobia W, Kenangalem E, Lampah DA, Warikar N, Seal A, McGready R, Sugiarto P, Tjitra E, Anstey NM, Price RN. Adverse pregnancy outcomes in an area where multidrug-resistant Plasmodium vivax and Plasmodium falciparum infections are endemic. Clin Infect Dis. 2008:46:1374-81.

4. Nosten F, McGready R, Simpson JA, Thwai KL, Balkan S, Cho T, Hkirijaroen L, Looareesuwan S, White NJ. Effects of Plasmodium vivax malaria in pregnancy. Lancet. 1999;354:546-9.

5. Syafruddin DAR. The burden of malaria in pregnancy in south west sumba and Yayapura District, Papua in Eastern Indonesia. Jakarta: UNICEF; 2010.

6. Bell D, Wongsrichanalai C, Barnwell JW. Ensuring quality and access for malaria diagnosis: how can it be achieved? Nat Rev Microbiol. 2006:4:682-95.

7. Moody A. Rapid diagnostic tests for malaria parasites. Clin Microbiol Rev 2002;15:66-78.

8. Bell DR, Wilson DW, Martin LB. False-positive results of a Plasmodium falciparum histidine-rich protein 2-detecting malaria rapid diagnostic test due to high sensitivity in a community with fluctuating low parasite density. Am J Trop Med Hyg. 2005;73:199-203.

9. Hopkins H, Bebell L, Kambale W, Dokomajilar C, Rosenthal PJ, Dorsey G Rapid diagnostic tests for malaria at sites of varying transmission intensity in Uganda. J Infect Dis. 2008;197:510-8.

10. Singh N, Shukla MM, Shukla MK, Mehra RK, Sharma S, Bharti PK, Singh MP, Singh A, Gunasekar A. Field and laboratory comparative evaluation of rapid malaria diagnostic tests versus traditional and molecular techniques in India. Malar J. 2010;9:191.

11. Taylor WRJ, Widjaja H, Basri H, Fryauff DJ, Ohrt C, Taufik, Tjitra E, Hoffman SL, Baso S, Richie TL. Assessing the Parasight (R)-F test in northeastern Papua, Indonesia, an area of mixed Plasmodium falciparum and Plasmodium vivax transmission. Am J Trop Med Hyg. 2002;66:649-52.
12. Tjitra E, Suprianto S, Dyer M, Currie BJ, Anstey NM. Field evaluation of the ICT malaria P.f/P.v immunochromatographic test for detection of Plasmodium falciparum and Plasmodium vivax in patients with a presumptive clinical diagnosis of malaria in eastern Indonesia. J Clin Microbiol. 1999;37:2412-7.

13. Kattenberg JH, Ochodo EA, Boer KR, Schallig HD, Mens PF, Leeflang MM. Systematic review and meta-analysis: rapid diagnostic tests versus placental histology, microscopy and PCR for malaria in pregnant women. Malar J. 2011;10:321.

14. Leke RFG, Djokam RR, Mbu R, Leke RJ, Fogako J, Megnekou R, Metenou S, Sama G, Zhou Y, Cadigan T, et al. Detection of the Plasmodium falciparum antigen histidine-rich protein 2 in blood of pregnant women: implications for diagnosing placental malaria. J Clin Microbiol. 1999;37:2992-6.

15. Mankhambo L, Kanjala M, Rudman S, Lema VM, Rogerson SJ. Evaluation of the OptiMAL rapid antigen test and species-specific PCR to detect placental Plasmodium falciparum infection at delivery. J Clin Microbiol. 2002;40:155-8.

16. Singer LM, Newman RD, Diarra A, Moran AC, Huber CS, Stennies G, Sirima SB, Konate A, Yameogo M, Sawadogo R, et al. Evaluation of a malaria rapid diagnostic test for assessing the burden of malaria during pregnancy. Am J Trop Med Hyg. 2004;70:481-5.

17. Dhorda M, Piola P, Nyehangane D, Tumwebaze B, Nalusaji A, Nabasumba C, Turyakira E, McGready R, Ashley E, Guerin PJ, Snounou G. Short report: performance of a histidine-rich protein 2 rapid diagnostic test, Paracheck Pf (R), for detection of malaria infections in Ugandan pregnant women. Am J Trop Med Hyg. 2012;86:93-5.

18. Tagbor H, Bruce J, Agbo M, Greenwood B, Chandramohan D. Intermittent screening and treatment versus intermittent preventive treatment of malaria in pregnancy: a randomised controlled non-inferiority trial. PLoS One. 2010;5:e14425.

19. Tagbor H, Bruce J, Browne E, Greenwood B, Chandramohan D. Performance of the OptiMAL dipstick in the diagnosis of malaria infection in pregnancy. Ther Clin Risk Manag. 2008;4:631-6.

20. VanderJagt TA, Ikeh EI, Ujah IO, Belmonte J, Glew RH, VanderJagt DJ. Comparison of the OptiMAL rapid test and microscopy for detection of malaria in pregnant women in Nigeria. Trop Med Int Health. 2005;10:39-41.

21. Ashley EA, Touabi M, Ahrer M, Hutagalung R, Htun K, Luchavez J, Dureza C, Proux S, Leimanis M, Lwin MM, et al. Evaluation of three parasite lactate dehydrogenase-based rapid diagnostic tests for the diagnosis of falciparum and vivax malaria. Malar J. 2009;8:241.

22. Cooke AH, Chiodini PL, Doherty T, Moody AH, Ries J, Pinder M. Comparison of a parasite lactate dehydrogenase-based immunochromatographic antigen detection assay (Optimal (R)) with microscopy for the detection of malaria parasites in human blood samples. Am J Trop Med Hyg 1999;60:173-6.

23. Iqbal J, Muneer A, Khalid N, Ahmed MA. Performance of the optimal test for malaria diagnosis among suspected malaria patients at the rural health centers. Am J Trop Med Hyg. 2003;68:624-8.

24. Syafruddin D, Krisin, Asih P, Sekartuti, Dewi RM, Coutrier F, Rozy IE, Susanti Al, Elyazar IR, Sutamihardja A, et al. Seasonal prevalence of malaria in West Sumba district, Indonesia. Malar J. 2009;8:8.

25. Who T. FIND: Malaria rapid diagnostic test performance : results of WHO product testing of malaria RDTs : round 3 (2010-2011). Geneva: World Health Organization; 2010.

26. Snounou G, Viriyakosol S, Zhu XP, Jarra W, Pinheiro L, Dorosario VE, Thaithong S, Brown KN. High-sensitivity of detection of human malaria parasites by the use of nested polymerase chain reactions. Mol Biochem Parasitol. 1993;61:315-20.

27. Rijken MJ, McGready R, Boel ME, Poespoprodjo R, Singh N, Syafruddin $D$, Rogerson S, Nosten F. Malaria in pregnancy in the Asia-Pacific region. Lancet Infect Dis. 2012;12:75-88.

28. Clinical Calculator-1. (http://vassarstats.net/clin1.html). Accessed 2 Oct 2015

29. Two way contingency table. (http://statpages.org/ctab2x2.html). Accessed 2 Oct 2015

30. Rutjes AWS, Reitsma JB, Di Nisio M, Smidt N, van Rijn JC, Bossuyt PMM. Evidence of bias and variation in diagnostic accuracy studies. Can Med Assoc J. 2006;174(4):469-76.

31. Hadgu A. Discrepant analysis is an inappropriate and unscientific method. J Clin Microbiol. 2001;38:4301-2. 
32. McAdam AJ. Discrepant analysis: how can we test a test? J Clin Microbiol. 2000;38:2027-9.

33. Hawkins DM, Garrett JA, Stephenson B. Some issues in resolution of diagnostic tests using an imperfect gold standard. Stat Med. 2001;20:1987-2001.

34. Bell D, Peeling RW. WHO-Regional Office for the Western Pacific/ TDR: evaluation of rapid diagnostic tests: malaria. Nat Rev Microbiol. 2006;4:S34-8.

35. Ratsimbasoa A, Randriamanantena A, Raherinjafy R, Rasoarilalao $\mathrm{N}$, Menard D. Which malaria rapid test for Madagascar? Field and laboratory evaluation of three tests and expert microscopy of samples from suspected malaria patients in Madagascar. Am J Trop Med Hyg 2007;76:481-5.

36. Cheng Q, Gatton ML, Barnwell J, Chiodini P, McCarthy J, Bell D, Cunningham J. Plasmodium falciparum parasites lacking histidine-rich protein 2 and 3: a review and recommendations for accurate reporting. Malar J. 2014;13:283.

37. Kumar N, Singh JP, Pande V, Mishra N, Srivastava B, Kapoor R, Valecha N, Anvikar AR. Genetic variation in histidine rich proteins among Indian Plasmodium falciparum population: possible cause of variable sensitivity of malaria rapid diagnostic tests. Malar J. 2012;11:298.
38. Mockenhaupt FP, Ulmen U, von Gaertner C, Bedu-Addo G, Bienzle U. Diagnosis of placental malaria. J Clin Microbiol. 2002;40:306-8.

39. Kattenberg JH, Tahita CM, Versteeg IA, Tinto $H$, Traore Coulibaly $M$, D'Alessandro U, Schallig HD, Mens PF. Evaluation of antigen detection tests, microscopy, and polymerase chain reaction for diagnosis of malaria in peripheral blood in asymptomatic pregnant women in Nanoro, Burkina Faso. Am J Trop Med Hyg. 2012;87:251-6.

40. Manirakiza A, Serdouma E, Heredeibona LS, Djalle D, Madji N, Moyen M, Soula G, Le Faou A, Delmont J. Rational case management of malaria with a rapid diagnostic test, Paracheck $P f(R)$, in antenatal health care in Bangui, Central African Republic. BMC Public Health. 2012;12:482.

41. Minja DT, Schmiegelow C, Oesterholt M, Magistrado PA, Bostrom S, John D, Pehrson C, Andersen D, Deloron P, Salanti A, et al. Reliability of rapid diagnostic tests in diagnosing pregnancy-associated malaria in northeastern Tanzania. Malar J. 2012;11:211.

42. Luchavez J, Lintag ME, Coll-Black M, Baik F, Bell D. An assessment of various blood collection and transfer methods used for malaria rapid diagnostic tests. Malar J. 2007;6:149.

\section{Submit your next manuscript to BioMed Central and take full advantage of:}

- Convenient online submission

- Thorough peer review

- No space constraints or color figure charges

- Immediate publication on acceptance

- Inclusion in PubMed, CAS, Scopus and Google Scholar

- Research which is freely available for redistribution

Submit your manuscript at

www.biomedcentral.com/submit

C Biomed Central 